\title{
Current Strategies in the Treatment of Intracranial Large and Giant Aneurysms
}

\author{
Matthias Gmeiner and Andreas Gruber
}

\section{Introduction}

Very large and giant intracranial aneurysms are defined as aneurysms with a diameter $>20 \mathrm{~mm}$ and $>25 \mathrm{~mm}$ [1] respectively. Giant aneurysms constitute approximately $2-5 \%$ of all intracranial aneurysms [2-4]. The natural history of these lesions is poor, with reported mortalities ranging from $66-80 \%$. The worst outcomes have been observed in untreated posterior circulation giant aneurysms [3-5]. The majority of patients harboring very large and giant intracranial aneurysms (50-80\%) present with thromboembolic events or symptoms of mass effect [3, 6], whereas subarachnoid hemorrhage $(\mathrm{SAH})$ occurs in approximately 20-30\% [6].

In view of the poor natural course of these lesions, aggressive treatment aiming for both aneurysm occlusion and relief of mass effect has been recommended $[6,7]$. The benefits of active aneurysm therapy must be weighed against the inherent risks of treatment. Whereas surgical management carried a significant morbidity and mortality in the past [3], recent meta-analyses reported good clinical outcomes in as many as $80 \%$ of the patients when individualized treatment strategies-including both surgical and endovascular techniques-were adopted [2]. The risk-benefit assessment, however, will favor active therapy only when treatment is performed at high-volume cerebrovascular centers, where the capacities of both neurosurgery and neurointervention are available and individualized treatment concepts considering anatomic location (cavernous vs. subarachnoid, anterior circulation vs. posterior circulation), clinical presentation (SAH vs. mass effect vs. incidental presentation), patient

M. Gmeiner · A. Gruber $(\bowtie)$

Department of Neurosurgery, Kepler University Hospital, Linz, Austria

Johannes Kepler University (JKU) Linz, Linz, Austria e-mail: matthias.gmeiner@kepleruniklinikum.at; andreas.gruber_1@kepleruniklinikum.at demographics (age), and aneurysm morphology can be applied $[6,7]$.

Both reconstructive (clipping, coiling, stent-assisted coiling, flow diversion [FD]) and deconstructive techniques (parent artery occlusion [PAO], PAO in conjunction with bypass surgery, and strategies of flow modification) are available for the treatment of cerebral aneurysms [8]. The aim of this paper is to review the current literature on the management of very large and giant aneurysms and to describe representative cases - treated by the senior author, who has been dually trained and is cross-experienced in both microsurgical and endovascular techniques - to illustrate possible treatment strategies.

\section{Reconstructive Techniques}

Reconstructive techniques are usually the preferred treatment strategy in the management of intracranial aneurysms, since these procedures do not compromise the patency of the parent vasculature and in turn do not interfere with cerebral blood flow distal to the aneurysm site. In the management of very large and giant aneurysms, open surgical strategies of direct aneurysm occlusion have proven technically difficult but often highly effective, whereas technically less challenging endovascular procedures, e.g., intrasaccular coil embolization, have proven ineffective in the long run. The role of more advanced endovascular strategies, e.g., FD stents and intra-aneurysmal FD, is still in the process of being defined.

\section{Clipping and Clip Reconstruction}

Direct surgical clip ligation of the neck with preservation of the parent vasculature remains the ideal reconstructive treatment strategy in the majority of very large and giant saccular aneurysms. Procedural outcomes usually depend on aneurysm morphology (calcifications, intrasaccular thrombus, 
complex anatomy), aneurysm location, parent artery caliber, and perforator anatomy $[4,6,9,10]$.

In the management of very large and giant middle cerebral artery (MCA) aneurysms, direct surgical clipping is considered the most effective and durable treatment, whereas coiling was identified as an independent risk factor for retreatment in a recent study describing the management of 106 large and giant MCA aneurysms [11]. Coiling of MCA aneurysms carries a higher recurrence risk even in smaller lesions. In detail, the recurrence risk following coil embolization of $>7 \mathrm{~mm}$ MCA aneurysms was $17.5 \%$ [12], and that of MCA aneurysms $\geq 11 \mathrm{~mm}$ was $46 \%$ in recent publications [13]. Long-term instability of MCA aneurysm occlusion was reported in $3 \%$ of the patients receiving surgical clipping and in $>45 \%$ of the patients receiving intrasaccular coiling [14].

The success of direct clipping of very large and giant aneurysms depends on the ability to soften the aneurysmal sac intraoperatively, usually achieved by temporary clipping of the parent vasculature or measures inducing transient cardiac standstill (i.e., pharmacologically induced hypodynamic standstill using Adenosine or electrically induced hyperdynamic standstill using rapid ventricular pacing). In cases of extensive intrasaccular thrombosis, aneurysmotomy and subsequent thrombectomy under pharmacologic cerebroprotection are required for successful clip reconstruction [6]. Multiple clips applied in different techniques (tandem clipping, stacked multiple clips, overlapping clips) are usually required (Fig. 1a-c) $[15,16]$.

\section{Coil Embolization}

Coil embolization has proven ineffective in the treatment of very large and giant aneurysms. Low initial complete occlusion rates (10-60\%) and high recanalization rates (56-90\%) have been demonstrated in several studies [17, 18]. Mechanisms of recanalization include coil compaction, coil migration, and aneurysm regrowth [18, 19].

In a previous study assessing the results of coil embolization in patients with very large or giant aneurysms, the senior author reported a $71 \%$ complete or nearly complete angiographic occlusion rate immediately after the intervention. Of note, a single embolization served as definitive treatment for only $12.5 \%$ of the giant and only $31 \%$ of the very large aneurysms in the long run [17]. In partially thrombosed aneurysms presenting with mass effect, selective coiling reportedly resulted in continuous aneurysm growth in $18 \%$ of the cases, whereas only $7 \%$ of the aneurysms decrease in size [20]. Coiling had little if any effect on the relief of symptoms of mass effect.

The current body of literature strongly suggests that the initial angiographic occlusion rate after coil embolization is related to the risk of re-rupture [21]. Ruptured aneurysms with angiographic occlusion rates $>90 \% 6$ months after coiling had low rates $(0.4 \%)$ of recurrent $\mathrm{SAH}$ within the subsequent 8 years [22]. In large and giant aneurysms, the reported annual rebleeding rate of $1.9 \%$ after coil embolization was substantially higher [23]. A retrospective study reporting outcomes after surgical or endovascular therapy of 184 very large or giant aneurysms identified the following as risk factors for incomplete angiographic obliteration: (1) fusiform aneurysm morphology, (2) aneurysm location in the posterior circulation, and (3) endovascular treatment (coiling or stent-assisted coiling) [24].

\section{Stent-Assisted Coiling}

Intrasaccular coil embolisation has significant limitations in wide-necked aneurysms due to comparably lower packing densities and subsequently higher rates of recanalization. Therefore, alternative techniques using so-called neck bridging devices have been introduced (Fig. 1d-f). The technique of stent-assisted coiling uses a stent-which per se is a nonocclusive device-to provide a scaffold to hold the coils within the aneurysmal sac [25]. Meta-analyses revealed that in patients harboring very large and giant aneurysms, occlusion rates were significantly higher following stent-assisted coiling [73\%] when compared to coiling alone (59\%) [26]. Of note, significantly higher treatment morbidities have been reported following stent-assisted coiling when compared to regular intrasaccular coil embolization [27]. Stent-assisted coiling has nowadays become a routine procedure that can be performed safely and effectively in expert hands. Since the implanted device is endoluminal rather than intraaneurysmal, peri-interventional management of coagulation is of major importance and procedure-related complications of in-stent thrombosis and subsequent distal thromboembolism are still relevant issues. When compared to flow diversion [FD], stent-assisted coiling of giant aneurysms has the potential to further increase aneurysmal mass effect. It should be pointed out that stent-assisted coiling of a giant aneurysm can be a very expensive undertaking.

\section{Flow Diversion}

Flow diverters have become an attractive alternative for the endovascular treatment of complex aneurysms in selected cases [28-31] because the technique does not suffer from the aforementioned shortcomings of intrasaccular coil embolization [17, 18, 20, 28]. Flow diverters initially received FDA approval for the treatment of large and giant aneurysms extending from the petrous to the superior hypophyseal segment of the internal carotid artery [32] (Fig. 1g-i). Currently, however, a variety of aneurysms-including those previously 

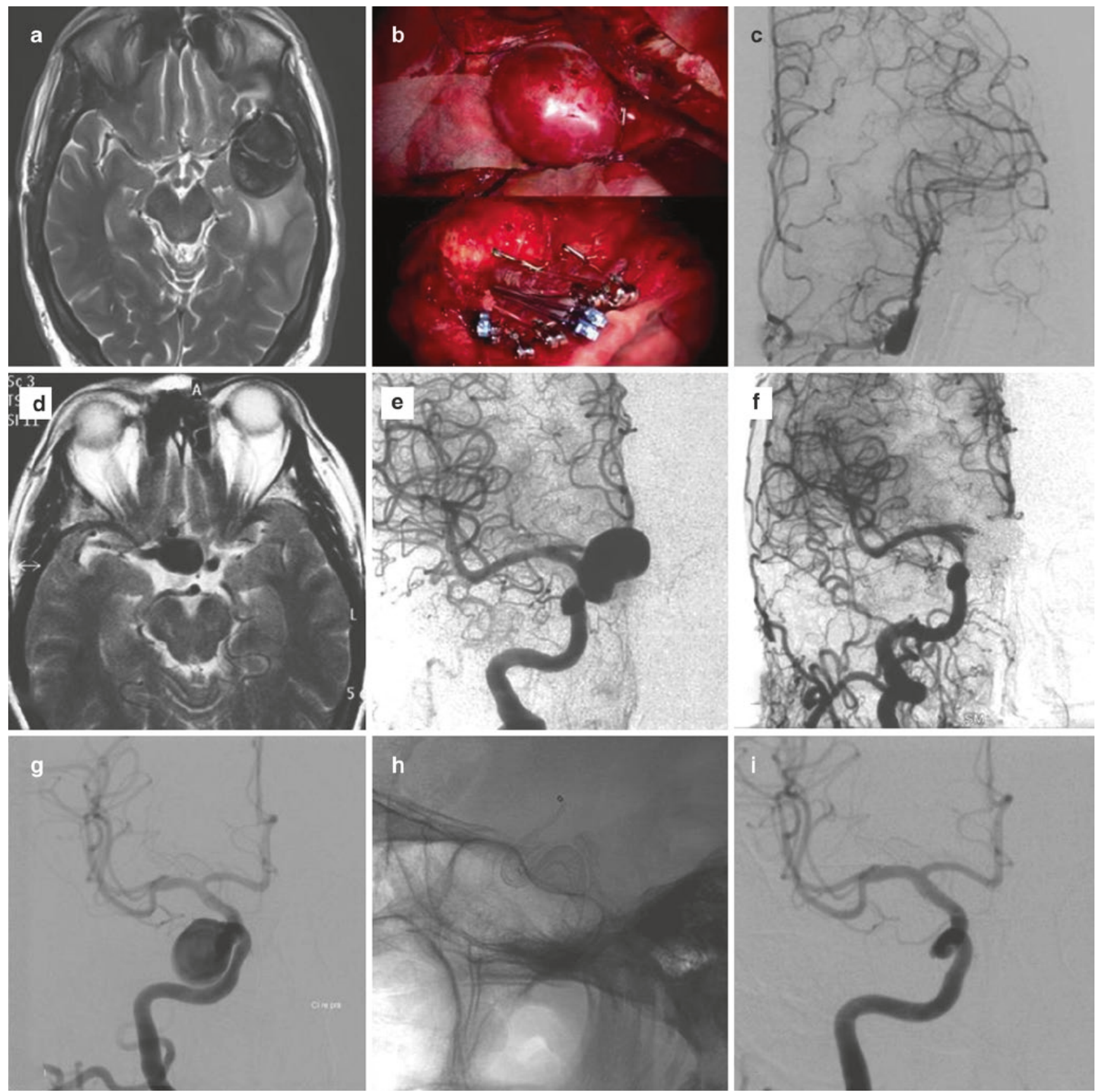

Fig. 1 Reconstructive surgical and endovascular techniques. (a-c) Microsurgical clipping. Fifteen years after uneventful clipping of a $7 \mathrm{~mm}$ left MCA bifurcation aneurysm, a $40 \mathrm{~mm}$ partially thrombosed aneurysm recurrence is detected on MRI (a). Since STA donor braches were of insufficient caliber and three M2 branches were incorporated into the aneurysm sac, the decision was made to treat the aneurysm by direct surgical clipping after temporary trapping, aneurysmotomy, and thrombectomy under pharmacologic cerebroprotection (b). Intraoperative left ICA angiograms demonstrate sufficient aneurysm obliteration (c) (A.G., procedure performed at the Kepler University Hospital Linz). (d-f) Stent-protected coil embolization. MRI (d) and right ICA angiograms (e) depict a $20 \mathrm{~mm}$ ICA aneurysm at the branch- ing site of the superior hypophyseal artery. Aneurysmal mass effect resulted in optic nerve compression and subsequent visual field deficits. The patient was treated by stent-protected coil embolization (f) and regained vision over the following months, an effect attributable to aneurysm shrinkage after embolization (A.G., procedure performed at the Medical University Vienna). (g-i) Flow diversion. Right ICA angiograms (g) demonstrate a very large intracavernous ICA aneurysm that resulted in partial ophthalmoplegia from mass effect and intracavernous cranial nerve compression. The patient was treated by FD stenting (h), which resulted in complete aneurysm occlusion (i) and delayed resolution of ophthalmoplegia due to post FD aneurysm shrinkage (A.G., procedure performed at the Medical University Vienna) 
treated, acutely ruptured, small sized, located within the posterior circulation, as well as non-saccular lesions including fusiform, dissecting, and pseudoaneurysms - are treated using FD techniques. For the time being, indications for FD treatment are unclear, and many procedures, especially those expanding FD indications from untreatable giant aneurysms to comparably easy surgical cases, must still be considered off-label uses of the device.

Similar to stent-assisted coiling, FD stenting relies on an endoluminal device creating an interface between the aneurysmal sac and the parent vasculature. Aneurysm occlusion thereby occurs in a delayed fashion over weeks to months [23] by intra-aneurysmal flow modification, thrombus formation, and subsequent endothelial overgrowth of the aneurysm neck. Peri-interventional management of coagulation, i.e., dual antiplatelet medication, is of major concern, and in turn FD stents have limited if any value in the management of patients with acutely ruptured aneurysms [33]. Since intra-aneurysmal thrombosis occurs progressively over time and intra-aneurysmal pressures will remain elevated even after the initial angiographic occlusion-which is due to stagnant aneurysmal inflow rather than to aneurysm obliteration ("a flow diverter is not a pressure diverter") [34]patients managed using FD stents in the acute phase after aneurysmal SAH are still at risk for early rebleeding.

Possible strategies to circumvent the problem of dual anti-platelet medication for FD treatment in acutely ruptured aneurysms include (1) techniques of intra-aneurysmal FD and (2) staged procedures consisting of partial protective coiling of the aneurysm dome in the acute phase followed by later definitive FD treatment. Such staged procedures were both safe and effective in a recent series of 31 patients with acutely ruptured intracranial aneurysms [35].

Unexplained cases of early post-interventional hemorrhages after FD treatment-occurring also in initially unruptured aneurysms and with often fatal consequences under dual anti-platelet medication-may also be explained by intrasaccular processes of active thrombus formation and degradation affecting the integrity of the aneurysm wall [3638]. These mechanisms remain speculative, however, since any residual flow within the aneurysm may per se trigger further aneurysm growth or rupture [39]. In line with these findings, a recent study demonstrated significantly improved occlusion rates in absence of post-interventional hemorrhages in patients undergoing FD stenting in conjunction with concomitant coiling when compared to FD treatment alone $(88.9 \%$ versus $61.5 \%$ complete occlusion rate, respectively) [31].

Similar mechanisms may trigger early giant aneurysm growth after FD treatment. A recent retrospective study found that 6 out of 45 aneurysms managed by FD stenting had increased $>20 \%$ in size during the first 6 months and produced symptoms of intracranial mass-effect [36]. Since other sources indicate that all aneurysms that underwent FD stenting either collapsed completely (in $90 \%$ of cases) or decreased significantly in size (in $10 \%$ of cases) between 6 and 18 months after the intervention, it is likely that the aforementioned mechanisms of post-FD stenting aneurysm expansion are transient in nature [38].

A recent study reported a $95.2 \%$ complete occlusion rate in complex internal carotid artery aneurysms undergoing FD stenting in absence of hemorrhagic or ischemic cerebrovascular events [28]. In the same patient cohort, the complete aneurysm occlusion rate after 180 days was $73.6 \%[28,40]$. Other reports have demonstrated complete aneurysm occlusions in as many as $76 \%$ of the giant aneurysms treated using FD stents. This success, however, came at the cost of comparably higher treatment morbidities when compared to those of conventional coil embolization. In detail, the reported procedure-related mortality was $5 \%$ and the overall ischemic stroke rate was 6\%. Perforator strokes occurred in $3 \%$ and patients with posterior circulation aneurysms were more likely to be affected. In basilar artery aneurysms, perforator territory strokes were encountered in 14\% [41]. The rates of post-procedural SAH or parenchymal hemorrhage were $3 \%$ each [29]. Aneurysm morphology may further influence the success of FD treatment. Recent data indicate that permanent complete aneurysm occlusion is less likely in aneurysms incorporating arterial side branches, i.e., in lesions where major arteries arising from the aneurysm are jailed during FD stent placement [42]. It should therefore be pointed out that the clinical safety of FD devices is still in a process of being defined [23]; e.g., a multicenter randomized care trial and registry was recently halted due to safety and efficacy concerns [43].

\section{Deconstructive Techniques}

Deconstructive measures are indicated only in those cases where reconstructive treatment of cerebral aneurysms is impossible or associated with unacceptable treatment morbidities. As previously mentioned, these strategies include $[10,44]$ therapeutic surgical or endovascular parent artery occlusion (PAO), PAO in conjunction with flow replacement bypass surgery, was well as techniques of flow modification (e.g., deliberate basilar trunk occlusion to induce flow reversal for the management of otherwise untreatable very large and giant basilar apex aneurysms).

\section{Parent Artery Occlusion}

As demonstrated in Fig. 2a-c, PAO relies on competent crossflow via anterior and posterior communicating artery collaterals as well as leptomeningeal anastomoses. The 

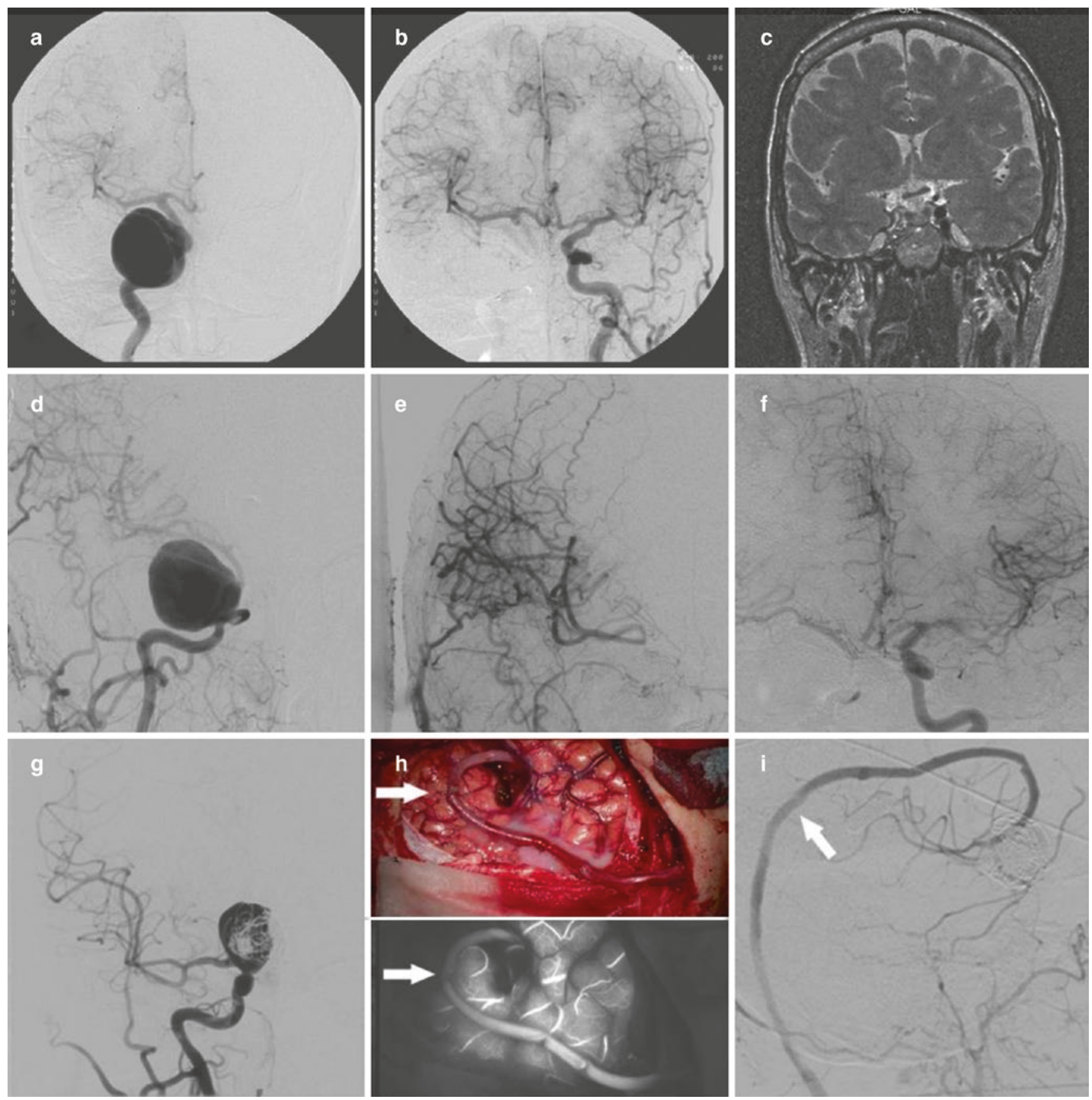

Fig. 2 Deconstructive surgical and endovascular techniques. (a-c) Parent artery occlusion. Right ICA angiograms (a) demonstrate a giant intracavernous ICA aneurysm that exerted local mass effect and resulted in complete right-sided ophthalmoplegia. The patient was managed by endovascular parent artery occlusion after successful balloon test occlusion. Left ICA angiograms (b) depict sufficient crossflow via the anterior communicating artery to supply the right hemisphere after therapeutic parent artery sacrifice (b). The intracavernous giant aneurysm decreased in size significantly as depicted on follow-up MRIs (c) and the patient's ophthalmoplegia gradually resolved over time (A.G., procedure performed at the Medical University Vienna). (d-f) Parent artery occlusion under low-flow bypass protection. Right ICA angiograms demonstrate a giant intracavernous ICA aneurysm (d) that became symptomatic by local cranial nerve compression and manifested in partial oculomotor nerve palsy. The patient was managed by
STA-MCA double-barrel low-flow bypass revascularization (e) $48 \mathrm{~h}$ before successful awake balloon test occlusion and subsequent endovascular parent artery occlusion. The bypass in conjunction with preexistent anterior communicating artery crossflow (f) was sufficient to revascularize the right hemisphere after therapeutic endovascular parent artery sacrifice (A.G., procedure performed at the Medical University Vienna). (g-i) Parent artery occlusion under venous highflow bypass protection. Right ICA angiograms depict a partially coiled, recurrent very large aneurysm of the right ICA at the branching site of the superior hypophyseal artery, exerting progressive optic nerve compression and resulting in right-sided visual loss (g). The patient was managed by saphenous vein high-flow bypass revascularization $(\mathbf{h}, \mathbf{i})$ followed by parent artery occlusion during the same procedure. The patient recovered gradually but never regained vision in her right eye (A.G., procedure performed at the Kepler University Hospital Linz) 
safety and feasibility of this strategy is assessed during balloon test occlusions [BTO] in the awake patient prior to definitive surgical or endovascular vessel sacrifice. Many surgeons, however, prefer revascularization in all cases that require major vessel sacrifice [44]. PAO is often followed by a significant reduction of aneurysm size and alleviation of aneurysmal compressive mass effect (Fig. 2a-c).

\section{Parent Artery Occlusion in Conjunction with Bypass Surgery}

In the vast majority of the cases, however, spontaneous collateral crossflow is inadequate to provide sufficient hemispheric blood flow distal to the point of PAO. In these cases, cerebral revascularization is required prior to PAO. Generally speaking, cerebral bypasses can be stratified according to their function (flow replacement bypass, flow augmentation bypass), their donor grafts (pedicled, interpositional, in situ), the sites of anastomosis (extracranial [EC]-intracranial [IC], EC-IC) and the flow provided (low-, intermediate-, and high flow) [44]. The revascularization technique selected for flow replacement bypass surgery in the management of intracerebral aneurysms depends on the treatment strategy chosen. In cases in which bypass surgery is performed in conjunction with surgical PAO during the same procedure (i.e., cases where neurologic assessment of the awake patient is not possible), high-flow bypass surgery is usually performed. It is reasonable to "oversize" the bypass rather than to face ischemic complications due to insufficient low-flow bypass revascularization (Fig. 2g-i). In those cases, however, where the therapeutic strategy involves cerebral revascularization 1-2 days ahead of BTO and endovascular PAO, other bypass techniques (i.e., double barrel STA-MCA bypass in cases of anterior circulation aneurysms, OA-PCA or OA-PICA bypasses in cases of posterior circulation aneurysms) may be justified. The senior author has successfully performed this technique in over 40 cases (Fig. 2d-f). Anterior and posterior communicating artery crossflow as well as leptomeningeal collaterals frequently contribute further to post PAO hemispheric revascularization.

The occlusion rates reported with indirect aneurysm treatment are high. A recent series described the management of 82 patients with complex intracranial aneurysms using both EC-IC and IC-IC bypasses and reported aneurysm obliteration rates of over $97 \%$ with low treatment-related morbidities [9]. Aneurysms managed by PAO in conjunction with bypass revascularization usually shrink in size over time. A recent multi-center study observed an average delayed volume reduction of $55.2 \%$ in giant aneurysms treated by PAO and bypass revascularization [1].

Whereas revascularization of multiple vascular territories distal to the site of PAO is usually easily obtained using the STA-MCA double-barrel technique (e.g., temporal and frontoparietal territories in cases of M1/M2 bifurcation aneurysms), this may be difficult in cases of - single-barrel-high-flow revascularization. Recent publications have reported a multiple reimplantation technique for the reconstruction of complex and giant MCA bifurcation aneurysms, where the efferent M2 branches are serially reimplanted into the saphenous vein donor graft [45]. The technical nuances of indirect surgical aneurysm occlusion were addressed in a recent publication, describing 18 different bypass strategies for the treatment of 30 complex MCA aneurysms, all managed with excellent surgical and clinical results [16].

Perforator occlusion in conjunction with PAO-induced thrombosis is always a major concern. A recent case series describing the management of 141 giant aneurysms reported thrombotic occlusion of perforators or branching arteries in $7 \%$ of the aneurysms receiving indirect treatment [10]. In those cases, where complete surgical trapping or endovascular coil embolization of the aneurysm is impossible due to delicate perforator anatomy, proximal or distal occlusions may be performed. This strategy relies on intra-aneurysmal flow modification to reduce the risk of aneurysm rupture, to induce slow aneurysm thrombosis, and to preserve flow into the perforating branches $[10,46]$. In some cases, however, postoperative aneurysm ruptures with devastating consequences have been reported with this technique [47].

Periprocedural ischemia due to prolonged temporary clipping times while suturing the anastomosis is another important issue. The larger the caliber of the donor graft (i.e., during high-flow bypass surgery), the larger-and thus more proximal - the recipient artery should be. In turn, the more proximal the recipient artery, (1) the larger the vascular territory rendered ischemic during temporary clipping for suturing the anastomosis, and (2) the more difficult and usually time-consuming the suturing of the anastomosis will be. To overcome this problem, the technique of excimer laserassisted non-occlusive anastomosis [ELANA] bypass was introduced to provide high-flow revascularization without cross-clamping related distal ischemia or stroke. The role of this technique, usually reserved for the most challenging lesions, is still in a process of being defined [44, 48]. In many cases, originally considered suitable for the ELANA procedure, FD stenting and other innovative reconstructive endovascular techniques have proven effective as well.

\section{Conclusion}

Very large and giant intracranial aneurysms are among the most challenging pathologies in neurosurgery. Patients harboring such lesions should be managed at high-volume cerebrovascular centers by multidisciplinary teams trained in all techniques of open and endovascular neurosurgery. 
In view of the poor natural history, active management using multiprofessional individualized approaches $[4,6,7$, $9-11,15,16,44-46,48-50]$ is required to achieve complete aneurysm occlusion, relief of mass effect, and obliteration of the embolic source with acceptable treatment morbidities [7]. Microsurgical and endovascular techniques are complementary rather than competitive strategies that can ideally be combined in hybrid procedures. Both microsurgery $[6,7,15,16]$ and neurointervention are still improving in technique and outcome. With an increasing endovascular caseload, neurosurgeons working in the field of cerebrovascular disease may find themselves in a "low case scenario" in the near future, where innovative strategies of surgical training-including haptic and virtual models of simulation [51]—will be of major importance to maintain the current levels of technical skill and procedural quality.

Conflict of Interest The authors declare that they have no conflict of interest or a financial disclosure.

\section{References}

1. Maldaner N, Guhl S, Mielke D, Musahl C, Schmidt NO, Wostrack M, Rufenacht DA, Vajkoczy P, Dengler J, Giant Intracranial Aneurysm Study G (2015) Changes in volume of giant intracranial aneurysms treated by surgical strategies other than direct clipping. Acta Neurochir 157:1117-1123; discussion 1123.

2. Dengler J, Maldaner N, Glasker S, Endres M, Wagner M, Malzahn U, Heuschmann PU, Vajkoczy P, Giant Intracranial Aneurysm Study G (2016) Outcome of surgical or endovascular treatment of giant intracranial aneurysms, with emphasis on age, aneurysm location, and unruptured aneuryms--a systematic review and metaanalysis. Cerebrovasc Dis 41:187-198

3. Lonjon M, Pennes F, Sedat J, Bataille B (2015) Epidemiology, genetic, natural history and clinical presentation of giant cerebral aneurysms. Neuro-Chirurgie 61:361-365

4. Velat GJ, Zabramski JM, Nakaji P, Spetzler RF (2012) Surgical management of giant posterior communicating artery aneurysms. Neurosurgery 71:43-50; discussion 51.

5. Greving JP, Wermer MJ, Brown RD Jr, Morita A, Juvela S, Yonekura M, Ishibashi T, Torner JC, Nakayama T, Rinkel GJ, Algra A (2014) Development of the PHASES score for prediction of risk of rupture of intracranial aneurysms: a pooled analysis of six prospective cohort studies. Lancet Neurol 13:59-66

6. Spetzler RF, Kalani MY, Nakaji P (2015) Neurovascular surgery. Thieme, New York, NY

7. Almefty K, Spetzler RF (2014) Management of giant internal carotid artery aneurysms. World Neurosurg 82:40-42

8. Gruber A, Knosp E (2016) Therapie rupturierter zerebraler Aneurysmen: Behandlungsoptionen und derzeitige Studienlage. J Neurol Neurochir Psychiatr 17:90-100

9. Sanai N, Zador Z, Lawton MT (2009) Bypass surgery for complex brain aneurysms: an assessment of intracranial-intracranial bypass. Neurosurgery 65:670-683; discussion 683.

10. Sughrue ME, Saloner D, Rayz VL, Lawton MT (2011) Giant intracranial aneurysms: evolution of management in a contemporary surgical series. Neurosurgery 69:1261-1270; discussion 1270-1.
11. Park W, Chung J, Ahn JS, Park JC, Kwun BD (2017) Treatment of large and giant middle cerebral artery aneurysms: risk factors for unfavorable outcomes. World Neurosurg 102:301-312

12. Kadkhodayan Y, Delgado Almandoz JE, Fease JL, Scholz JM, Blem AM, Tran K, Crandall BM, Tubman DE (2015) Endovascular treatment of 346 middle cerebral artery aneurysms: results of a 16-year single-center experience. Neurosurgery 76:54-60; discussion 60-1.

13. Iijima A, Piotin M, Mounayer C, Spelle L, Weill A, Moret J (2005) Endovascular treatment with coils of 149 middle cerebral artery berry aneurysms. Radiology 237:611-619

14. Smith TR, Cote DJ, Dasenbrock HH, Hamade YJ, Zammar SG, El Tecle NE, Batjer HH, Bendok BR (2015) Comparison of the efficacy and safety of endovascular coiling versus microsurgical clipping for unruptured middle cerebral artery aneurysms: a systematic review and meta-analysis. World Neurosurg 84:942-953

15. Lawton MT (2010) Seven aneurysms. Tenets and techniques for clipping. Thieme, New York, NY

16. Tayebi Meybodi A, Huang W, Benet A, Kola O, Lawton MT (2017) Bypass surgery for complex middle cerebral artery aneurysms: an algorithmic approach to revascularization. J Neurosurg 127:463-479

17. Gruber A, Killer M, Bavinzski G, Richling B (1999) Clinical and angiographic results of endosaccular coiling treatment of giant and very large intracranial aneurysms: a 7-year, single-center experience. Neurosurgery 45:793-803; discussion 803-4.

18. Wang B, Gao BL, Xu GP, Xiang C, Liu XS (2015) Endovascular embolization is applicable for large and giant intracranial aneurysms: experience in one center with long-term angiographic follow-up. Acta Radiol 56:105-113

19. Dorfer C, Gruber A, Standhardt H, Bavinzski G, Knosp E (2012) Management of residual and recurrent aneurysms after initial endovascular treatment. Neurosurgery 70:537-553; discussion 553-4.

20. Ferns SP, van Rooij WJ, Sluzewski M, van den Berg R, Majoie CB (2010) Partially thrombosed intracranial aneurysms presenting with mass effect: long-term clinical and imaging follow-up after endovascular treatment. AJNR Am J Neuroradiol 31:1197-1205

21. Johnston SC, Dowd CF, Higashida RT, Lawton MT, Duckwiler GR, Gress DR, Investigators C (2008) Predictors of rehemorrhage after treatment of ruptured intracranial aneurysms: the Cerebral Aneurysm Rerupture After Treatment (CARAT) study. Stroke 39:120-125

22. Schaafsma JD, Sprengers ME, van Rooij WJ, Sluzewski M, Majoie CB, Wermer MJ, Rinkel GJ (2009) Long-term recurrent subarachnoid hemorrhage after adequate coiling versus clipping of ruptured intracranial aneurysms. Stroke 40:1758-1763

23. Mazur MD, Taussky P, Park MS, Couldwell WT (2018) Contemporary endovascular and open aneurysm treatment in the era of flow diversion. J Neurol Neurosurg Psychiatry 89:277-286

24. Darsaut TE, Darsaut NM, Chang SD, Silverberg GD, Shuer LM, Tian L, Dodd RL, Do HM, Marks MP, Steinberg GK (2011) Predictors of clinical and angiographic outcome after surgical or endovascular therapy of very large and giant intracranial aneurysms. Neurosurgery 68:903-915

25. Hong Y, Wang YJ, Deng Z, Wu Q, Zhang JM (2014) Stent-assisted coiling versus coiling in treatment of intracranial aneurysm: a systematic review and meta-analysis. PLoS One 9:e82311

26. Cagnazzo F, Mantilla D, Rouchaud A, Brinjikji W, Lefevre PH, Dargazanli C, Gascou G, Riquelme C, Perrini P, di Carlo D, Bonafe A, Costalat V (2018) Endovascular treatment of very large and giant intracranial aneurysms: comparison between reconstructive and deconstructive techniques-a meta-analysis. AJNR Am J Neuroradiol 39:852-858

27. Piotin M, Blanc R, Spelle L, Mounayer C, Piantino R, Schmidt PJ, Moret J (2010) Stent-assisted coiling of intracranial aneurysms: clinical and angiographic results in 216 consecutive aneurysms. Stroke 41:110-115 
28. Becske T, Brinjikji W, Potts MB, Kallmes DF, Shapiro M, Moran CJ, Levy EI, McDougall CG, Szikora I, Lanzino G, Woo HH, Lopes DK, Siddiqui AH, Albuquerque FC, Fiorella DJ, Saatci I, Cekirge SH, Berez AL, Cher DJ, Berentei Z, Marosfoi M, Nelson PK (2017) Long-term clinical and angiographic outcomes following pipeline embolization device treatment of complex internal carotid artery aneurysms: five-year results of the pipeline for uncoilable or failed aneurysms trial. Neurosurgery 80:40-48

29. Brinjikji W, Murad MH, Lanzino G, Cloft HJ, Kallmes DF (2013) Endovascular treatment of intracranial aneurysms with flow diverters: a meta-analysis. Stroke 44:442-447

30. Oishi H, Teranishi K, Yatomi K, Fujii T, Yamamoto M, Arai H (2018) Flow diverter therapy using a pipeline embolization device for 100 unruptured large and giant internal carotid artery aneurysms in a single center in a Japanese population. Neurol Med Chir 58:461-467

31. Peschillo S, Caporlingua A, Resta MC, Peluso JPP, Burdi N, Sourour N, Diana F, Guidetti G, Clarencon F, Bloemsma GC, Di Maria F, Donatelli M, Resta M (2017) Endovascular treatment of large and giant carotid aneurysms with flow-diverter stents alone or in combination with coils: a multicenter experience and long-term follow-up. Oper Neurosurg 13:492-502

32. Patel PD, Chalouhi N, Atallah E, Tjoumakaris S, Hasan D, Zarzour H, Rosenwasser R, Jabbour P (2017) Off-label uses of the Pipeline embolization device: a review of the literature. Neurosurg Focus 42:E4

33. Kulcsar Z, Wetzel SG, Augsburger L, Gruber A, Wanke I, Rufenacht DA (2010) Effect of flow diversion treatment on very small ruptured aneurysms. Neurosurgery 67:789-793

34. Kerl HU, Boll H, Fiebig T, Figueiredo G, Forster A, Nolte IS, Nonn A, Groden C, Brockmann MA (2014) Implantation of pipeline flow-diverting stents reduces aneurysm inflow without relevantly affecting static intra-aneurysmal pressure. Neurosurgery 74:321334; discussion 334.

35. Brinjikji W, Piano M, Fang S, Pero G, Kallmes DF, Quilici L, Valvassori L, Lozupone E, Cloft HJ, Boccardi E, Lanzino G (2016) Treatment of ruptured complex and large/giant ruptured cerebral aneurysms by acute coiling followed by staged flow diversion. J Neurosurg 125:120-127

36. de Korte AM, Aquarius R, Meijer FJA, Boogaarts HD, de Vries J (2018) Intracranial aneurysm expansion might cause neurological deterioration after flow diverter treatment. World Neurosurg 120:e802-e810

37. Kulcsar Z, Houdart E, Bonafe A, Parker G, Millar J, Goddard AJ, Renowden S, Gal G, Turowski B, Mitchell K, Gray F, Rodriguez M, van den Berg R, Gruber A, Desal H, Wanke I, Rufenacht DA (2011) Intra-aneurysmal thrombosis as a possible cause of delayed aneurysm rupture after flow-diversion treatment. AJNR Am J Neuroradiol 32:20-25

38. Szikora I, Marosfoi M, Salomvary B, Berentei Z, Gubucz I (2013) Resolution of mass effect and compression symptoms following endoluminal flow diversion for the treatment of intracranial aneurysms. AJNR Am J Neuroradiol 34:935-939
39. Hampton T, Walsh D, Tolias C, Fiorella D (2018) Mural destabilization after aneurysm treatment with a flow-diverting device: a report of two cases. J Neurointerv Surg 10:i51-i55

40. Becske T, Kallmes DF, Saatci I, McDougall CG, Szikora I, Lanzino G, Moran CJ, Woo HH, Lopes DK, Berez AL, Cher DJ, Siddiqui AH, Levy EI, Albuquerque FC, Fiorella DJ, Berentei Z, Marosfoi M, Cekirge SH, Nelson PK (2013) Pipeline for uncoilable or failed aneurysms: results from a multicenter clinical trial. Radiology 267:858-868

41. Phillips TJ, Wenderoth JD, Phatouros CC, Rice H, Singh TP, Devilliers L, Wycoco V, Meckel S, McAuliffe W (2012) Safety of the pipeline embolization device in treatment of posterior circulation aneurysms. AJNR Am J Neuroradiol 33:1225-1231

42. Trivelato FP, Salles Rezende MT, Ulhoa AC, Henrique de CastroAfonso L, Nakiri GS, Abud DG (2018) Occlusion rates of intracranial aneurysms treated with the Pipeline embolization device: the role of branches arising from the sac. J Neurosurg 130:543-549

43. Raymond J, Gentric JC, Darsaut TE, Iancu D, Chagnon M, Weill A, Roy D (2017) Flow diversion in the treatment of aneurysms: a randomized care trial and registry. J Neurosurg 127:454-462

44. Thines L, Proust F, Marinho P, Durand A, van der Zwan A, Regli L, Lejeune JP (2016) Giant and complex aneurysms treatment with preservation of flow via bypass technique. Neuro-Chirurgie 62:1-13

45. Kato N, Prinz V, Finger T, Schomacher M, Onken J, Dengler J, Jakob W, Vajkoczy P (2013) Multiple reimplantation technique for treatment of complex giant aneurysms of the middle cerebral artery: technical note. Acta Neurochir 155:261-269

46. Esposito G, Fierstra J, Regli L (2016) Distal outflow occlusion with bypass revascularization: last resort measure in managing complex MCA and PICA aneurysms. Acta Neurochir 158:1523-1531

47. Shakur SF, Carlson AP, Harris D, Alaraj A, Charbel FT (2017) Rupture after bypass and distal occlusion of giant anterior circulation aneurysms. World Neurosurg 105:1040.e1047-1040.e1013

48. van Doormaal TP, van der Zwan A, Verweij BH, Regli L, Tulleken CA (2010) Giant aneurysm clipping under protection of an excimer laser-assisted non-occlusive anastomosis bypass. Neurosurgery 66:439-447; discussion 447.

49. Kalani MY, Zabramski JM, Hu YC, Spetzler RF (2013) Extracranialintracranial bypass and vessel occlusion for the treatment of unclippable giant middle cerebral artery aneurysms. Neurosurgery 72:428-435; discussion 435-6.

50. Lejeune JP, Thines L, Proust F, Riegel B, Koussa M, Decoene C (2016) Selective microsurgical treatment of giant intracranial aneurysms. Neuro-Chirurgie 62:30-37

51. Gmeiner M, Dirnberger J, Fenz W, Gollwitzer M, Wurm G, Trenkler J, Gruber A (2018) Virtual cerebral aneurysm clipping with real-time haptic force feedback in neurosurgical education. World Neurosurg 112:e313-e323

Open Access This chapter is licensed under the terms of the Creative Commons Attribution 4.0 International License (http://creativecommons. org/licenses/by/4.0/), which permits use, sharing, adaptation, distribution and reproduction in any medium or format, as long as you give appropriate credit to the original author(s) and the source, provide a link to the Creative Commons license and indicate if changes were made.

The images or other third party material in this chapter are included in the chapter's Creative Commons license, unless indicated otherwise in a credit line to the material. If material is not included in the chapter's Creative Commons license and your intended use is not permitted by statutory regulation or exceeds the permitted use, you will need to obtain permission directly from the copyright holder. 